\title{
Multidisciplinary Treatment Approach of a Patient with Amelogenesis Imperfecta Superimposed by Thumb Sucking Habit: A Case Report
}

\author{
Raed R. Gholman', BDS, SBPD, and Omar A. El Meligy 2,3, MSc, PhD \\ 'King Abdulaziz Medical City, Jeddah, Saudi Arabia \\ ${ }^{2}$ Department of Pediatric Dentistry, Faculty of Dentistry, King Abdulaziz University, Jeddah, Saudi Arabia \\ ${ }^{3}$ Faculty of Dentistry, Alexandria University, Alexandria, Egypt
}

\section{Correspondence \\ Prof. Omar A. El Meligy \\ P.O. Box 80209, Jeddah 21589 \\ Saudi Arabia \\ e.M: omeligy@kau.edu.sa \\ $\begin{array}{ll}\text { Submission: } & 14 \text { August } 2017 \\ \text { Accepted: } & 30 \text { August } 2017\end{array}$}

\section{Citation}

Gholman RR, El Meligy OE. Multidisciplinary treatment approach of a patient with amelogenesis imperfecta superimposed by thumb sucking habit: a case report. JKAU Med Sci 2017; 24 (4): 31-39. DOI: 10.4197/Med. 24.4.5

\begin{abstract}
A seven-year-old boy was presented with discontent of his teeth appearance, mild teeth sensitiveness, bad masticatory effectiveness, difficulty in speech and low self-esteem. The clinical and radiographic results indicated amelogenesis imperfecta. Because of uncooperative behavior, treatment was accomplished under general anesthesia. The use of composite resin and stainless steel crowns produced effective and satisfying improvement of the patient's aesthetic looks, in addition to prevention of further sensitivity and wear so enhancing his functional needs. The lastingness of the thorough management of this patient needed powerful stress on careful oral hygiene. There is a major role of multidisciplinary team to the effective management of patients with hypomaturation type of amelogenesis imperfecta. Many factors have a significant part in treatment planning of amelogenesis imperfecta cases such as patient's age, socioeconomic condition, seriousness of the defect, the patient's collaboration and association with other medical conditions.
\end{abstract}

\section{Keywords}

Amelogenesis imperfecta; Thumb sucking habit; Stainless steel crowns; Composite resin

\begin{abstract}
Introduction
melogenesis imperfecta (Al) is a congenital disorder that interferes with normal enamel formation in the absence of a systemic disorder. Generally, it affects most or all of the teeth in both the primary and permanent dentitions ${ }^{[1]}$. Amelogenesis imperfecta may be inherited by $\mathrm{x}$-linked or sporadic inheritance. The different clinical manifestations of $\mathrm{Al}$ have a specific gene anomaly associated with each phenotype. Specific mutations proven to cause Al
\end{abstract}

include: amelogenin (AMELX), enamelin (ENAM), kallikrein4 (KLK4), enamelysis (MMP-20) and FAM83H ${ }^{[2]}$. Although $\mathrm{Al}$ is an uncommon pathological dental defect (its prevalence extends from 1 in 2000 up to 1 in $18,000$ patients $)^{[3]}$, its classification, causes, clinical and treatment features have been discussed considerably in the scientific publications. The cause and effect association of atypical dentoskeletal features is of major value for the clinician in Al patients, particularly in open bite cases. 
The generally recognized classification of $\mathrm{Al}$ comprises three forms: hypocalcified (normal thickness, smooth surface, less hardness), hypoplastic (reduced thickness, smooth surface, normal hardness) and hypomaturation (normal thickness, chipped surface, less hardness, opaque white coloration $)^{[4]}$. Classification depends mostly on many factors, such as phenotypical malformations and molecular defects, mode of inheritance, biochemical examination of the enamel and not only the clinical aspect of the enamel ${ }^{[5]}$. In most of the studies, the number of Al subtypes referred to is $12^{[6]}$. So far, at least 15 forms of $\mathrm{Al}$ have been reported based on clinical features and inheritance pattern ${ }^{[7]}$.

\section{Case Report}

A seven year-old uncooperative Saudi boy (Fig. 1) was referred to King Abdulaziz Medical City (KAMC) dental clinics from a primary health care center presented with dissatisfaction of his teeth appearance, mild posterior teeth sensitivity, poor masticatory efficiency, difficulty in speech and low self-esteem. He was referred to pediatric ophthalmologist, orthopedic and nephrologist to rule out any medical conditions, and cleared for treatment under general anesthesia (GA) with no special considerations except for feet toes syndactyly which will be surgically separated later.

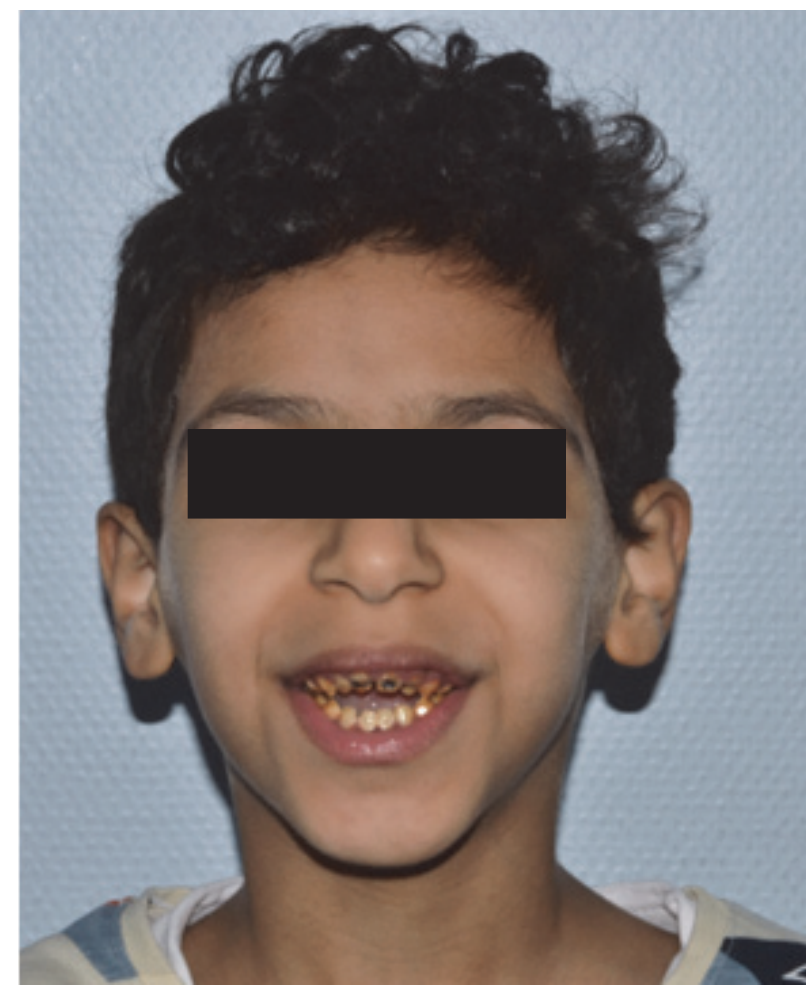

Figure 1. Extra-oral picture of the patient.
Extra-oral examination revealed long face, feet syndactyly (Fig. 2) and indentation on his thumb due to thumb sucking habit (Fig. 3). Intra-oral clinical (Fig. 4) and radiographic (Fig. 5 and 6) examination revealed bad oral hygiene with excessive plaque and calculus deposition, which caused generalized gingivitis. Teeth exhibited short clinical crowns with wide areas of thin, yellow, brown or grey, hypoplastic and chipped enamel

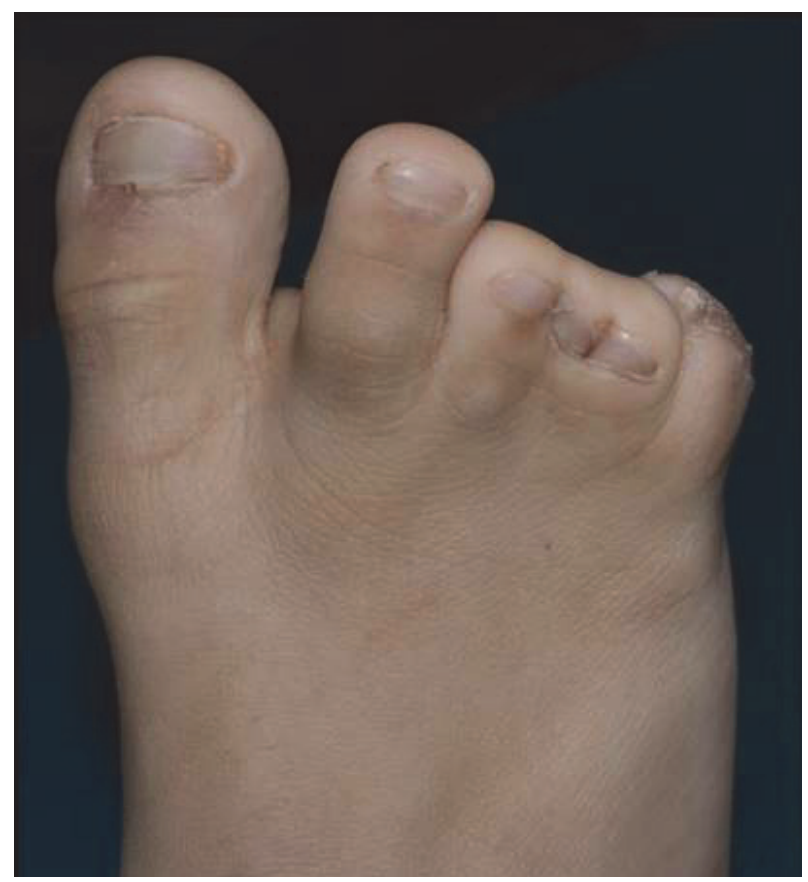

Figure 2. Foot syndactyly.

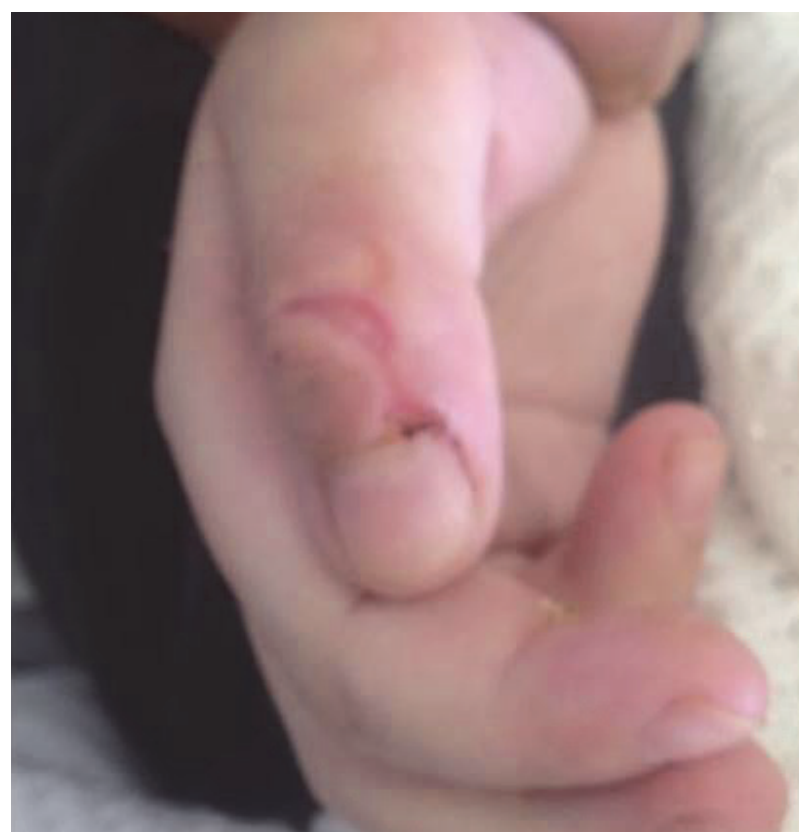

Figure 3. Thumb injury. 

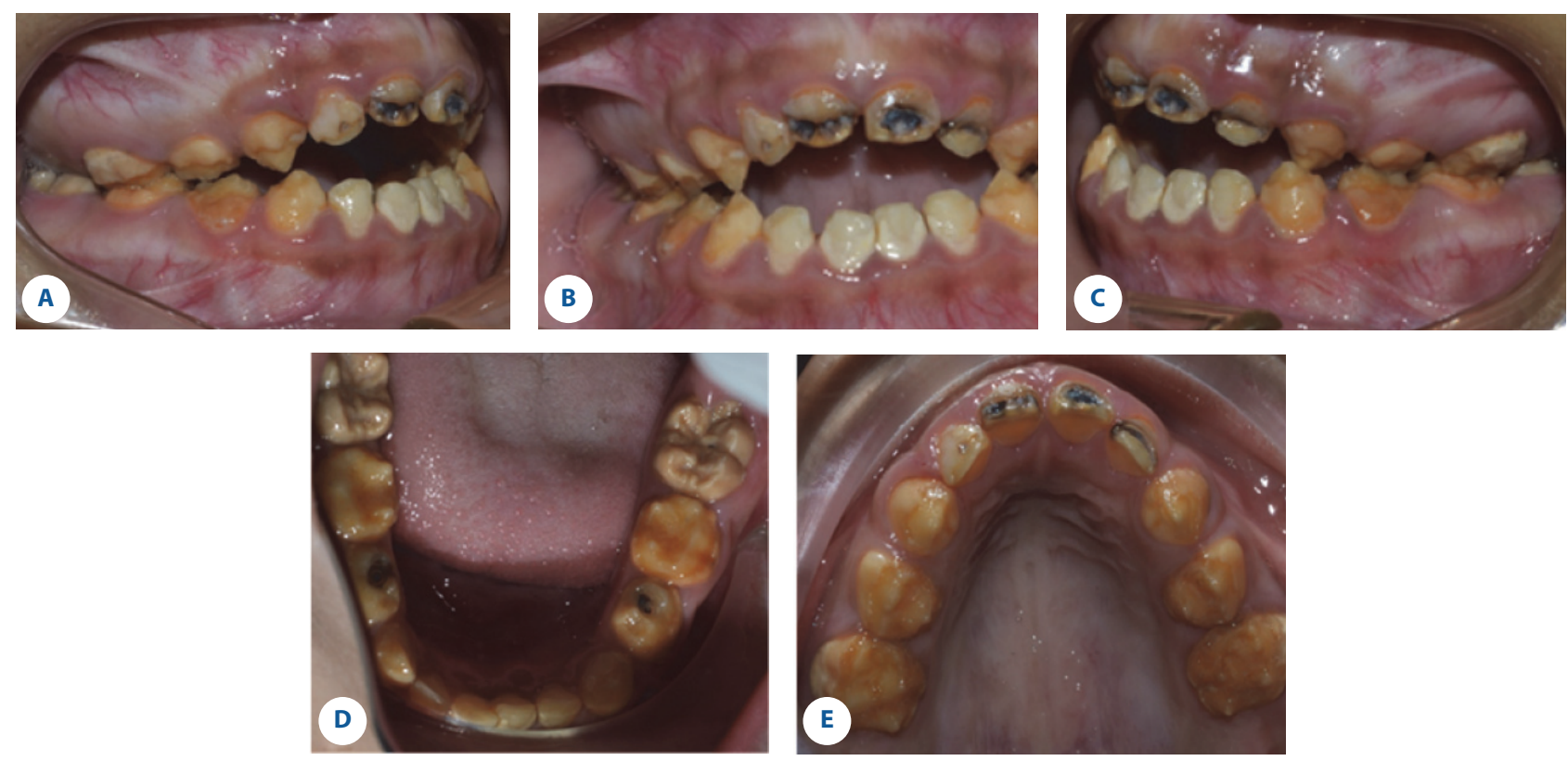

Figure 4A-E. Intra-oral preoperative clinical pictures of affected teeth.

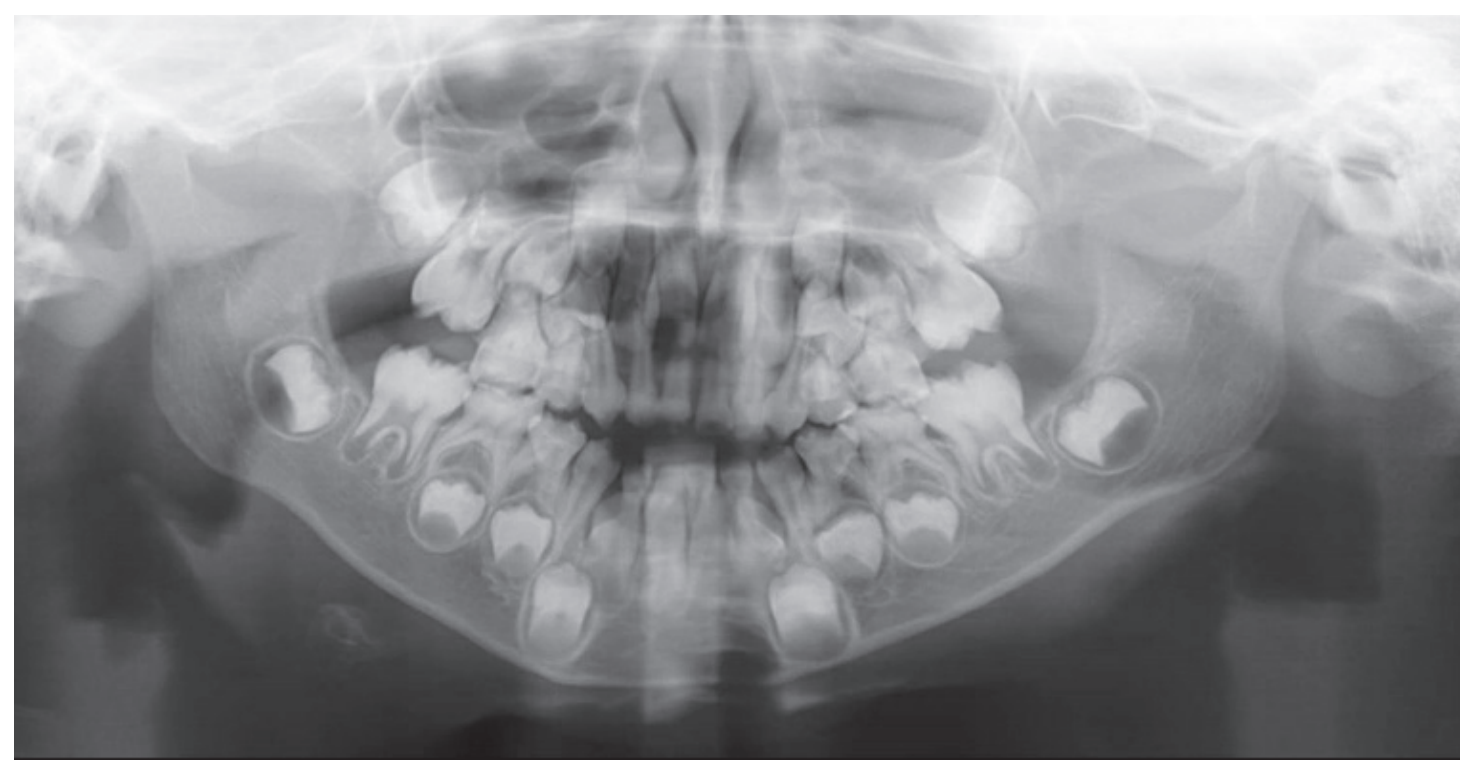

Figure 5. Pre-operative panoramic radiograph.

as well as exposed dentin in posterior teeth and dental caries.

Early loss of vertical dimension, in addition to an open bite of $15 \mathrm{~mm}$ and an over jet of $1 \mathrm{~mm}$, constricted maxilla and bilateral posterior cross bite were evident. A mesial step primary molar relationship with class II canine relationship. The first panoramic, cephalogram, bitewing and periapical radiographic examination (Fig. 5, 6 and 7), revealed an early permanent dentition period, with all permanent teeth present and covered by thin layer of enamel. The underlying dentin-pulp complex seemed normal. The dental age of this patient is late compared to his chronologic age.

\section{Discussion}

The clinical and radiographic results indicated a hereditary enamel disorder i.e., Al depending on the Witkop's classification ${ }^{[8]}$, diagnosis of hypomaturation 


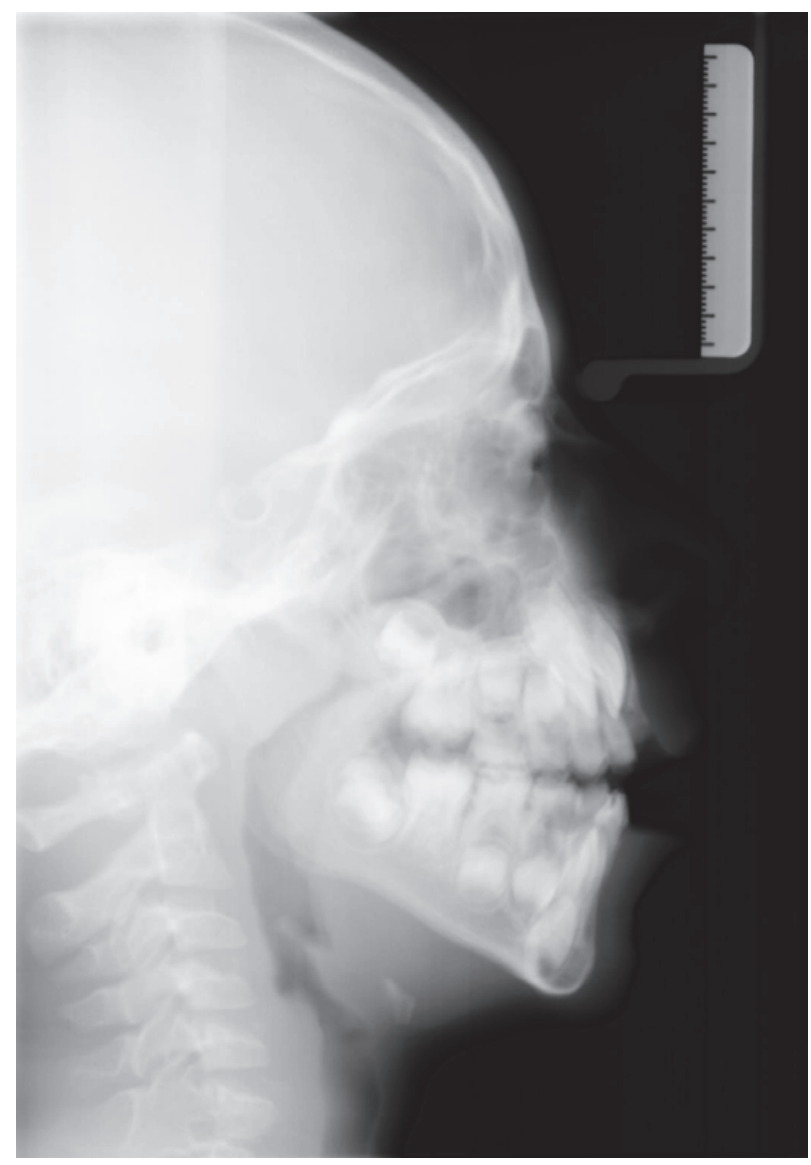

Figure 6. Pre-operative cephalogram

type of Al was done. Caries risk was evaluated by interviewing the parents and patient concerning oral hygiene, diet and general lifestyle habits. The patient was categorized as a high-risk group by the evaluation, depending on several predisposing factors, with Al the most important of all.

Multidisciplinary approach for best treatment outcomes was accomplished with multiple treatment alternatives that have been suggested in the literature. Alternatives varied from simple microabrasion ${ }^{[9]}$, to resin-based composites ${ }^{[10]}$ and Stainless steel crowns $(\mathrm{SSCs})^{[11]}$. All ceramic crowns ${ }^{[12]}$, metal-ceramic crowns $^{[13]}$, and veneers ${ }^{[14]}$ might be considered in the future upon eruption of permanent dentition. Several case reports have concentrated on the early treatment of children and adolescents, and the utilization of bonded restorations has increased popularity because of numerous advantages associated with these materials; conservative approach, superior aesthetics and enhanced wear make their use favorable $e^{[10,11]}$.
Pediatric dentists, prosthodontics and orthodontics contributed in treatment planning. The primary objective of treatment was to provide restorations for the preservation of remaining tooth structure against further sensitivity and wear. Restoration of anterior teeth with composite resin to enhance the patients' aesthetic, in addition to full coverage of posterior primary and permanent molars with SSCs and extraction of exfoliating primary teeth was the ideal treatment option at this time. Orthodontic consultation was done regarding the open bite and the treatment aim was to break the habit in addition to maxillary expansion to correct the posterior cross bite and open bite either by rapid or slow palatal expanders with the superiority to slow palatal expander due to the possibility of combining two appliances together to correct both maxillary constriction and open bite.

Prior to treatment, a written informed consent was obtained from the parents.

The sequence of treatment accomplished under GA was as follows:

1. Composite resin in affected anterior teeth. Five percent sodium hypochlorite $(\mathrm{NaClO})$ solution was applied for one minute on the tooth structure to enhance bonding between composite restoration and tooth structure ${ }^{[15]}$.

2. Ferric sulfate pulpotomy in teeth \#74 and \#84.

3. SSCs in posterior primary and permanent molars.

4. Extraction of anterior exfoliating carious teeth \#51, \#61, \#71, \#72, \#81 and \#82.

5. Impressions were taken to construct orthodontic casts.

6. The patient was given instructions regarding thumb sucking habit effects on dentofacial structures post-operatively in the pediatric ward.

In the 3 months' recall, patient cooperation was gained once more using tell-show and do (TSD), positive reinforcement and rewarding approaches with a positive history of thumb sucking habit.

The following procedures were done:

1. Bands selection and impressions were taken to construct a versatile modified quad-helix appliance. The appliance was constructed using a 0.036 -inch stainless wire incorporating palatal 
Multidisciplinary Treatment Approach of a Patient with Amelogenesis Imperfecta Superimposed by Thumb Sucking Habit... R.R. Gholman and O.A. El Meligy
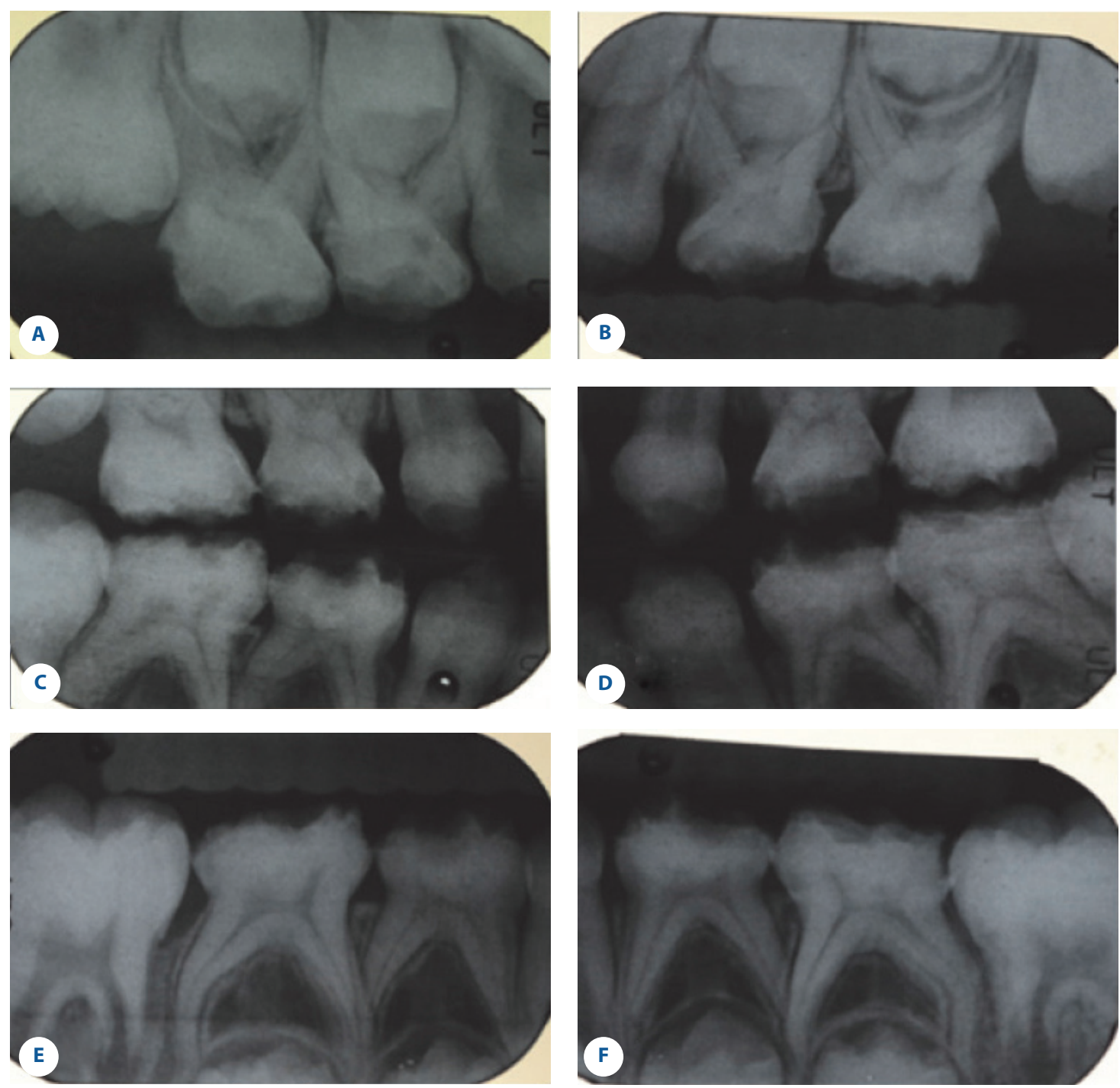

Figure 7A-F. Pre-operative periapical and bitewing views.

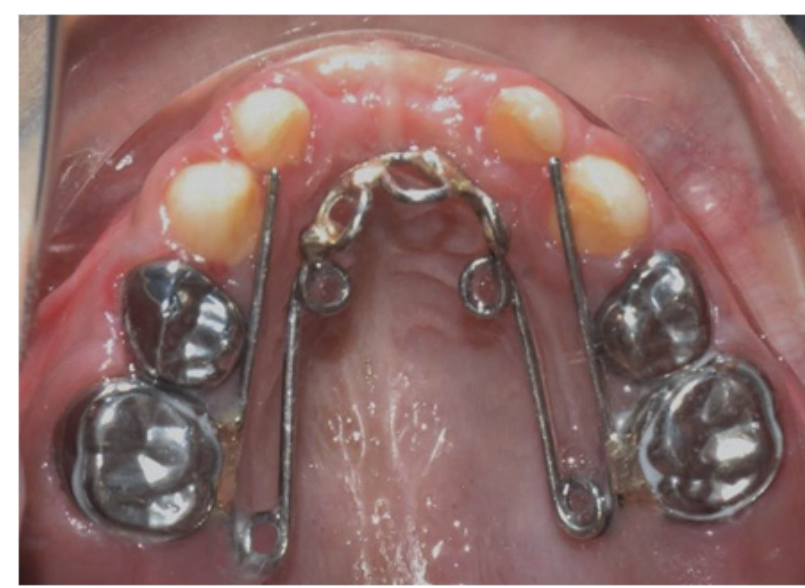

Figure 8. Insertion of a versatile modified quad-helix appliance. 
Multidisciplinary Treatment Approach of a Patient with Amelogenesis Imperfecta Superimposed by Thumb Sucking Habit... R.R. Gholman and O.A. El Meligy
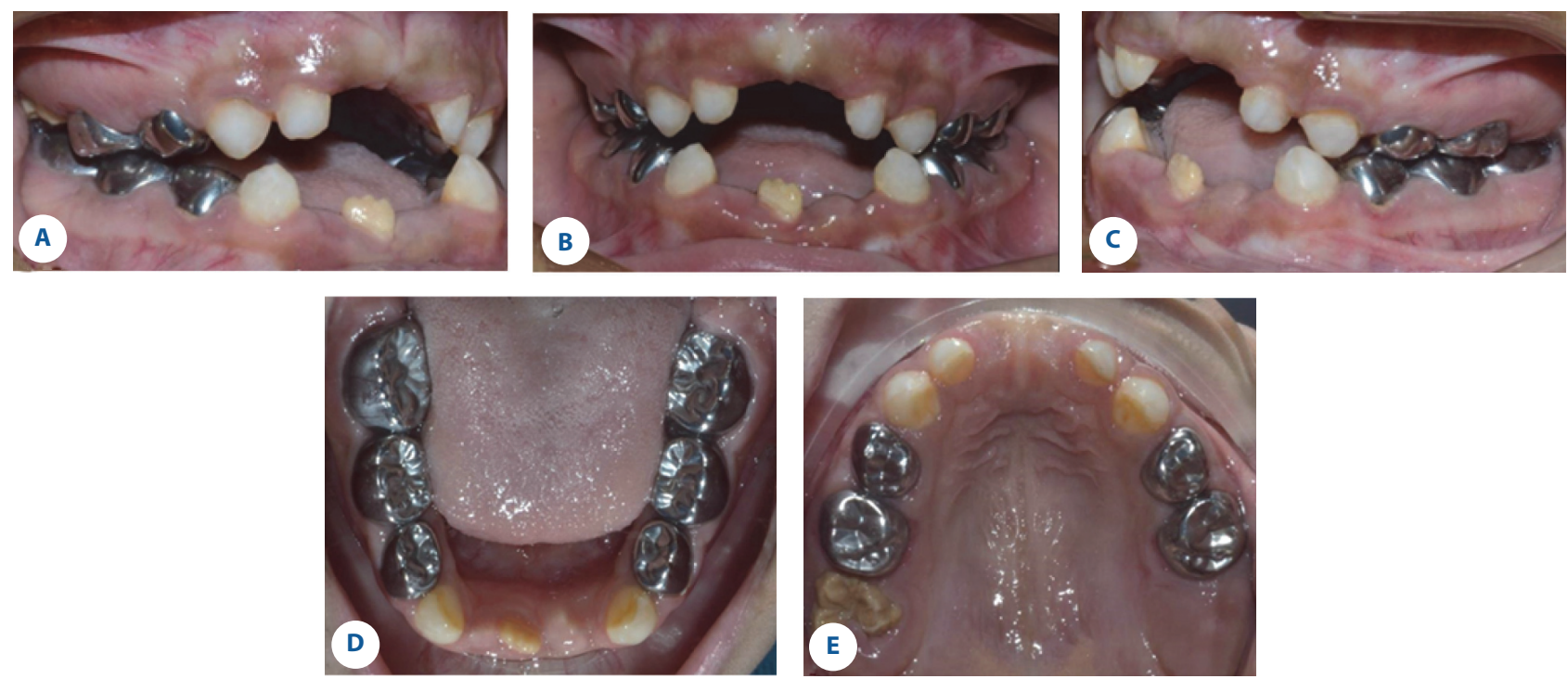

Figure 9A-E. Three months' post-operative clinical pictures.
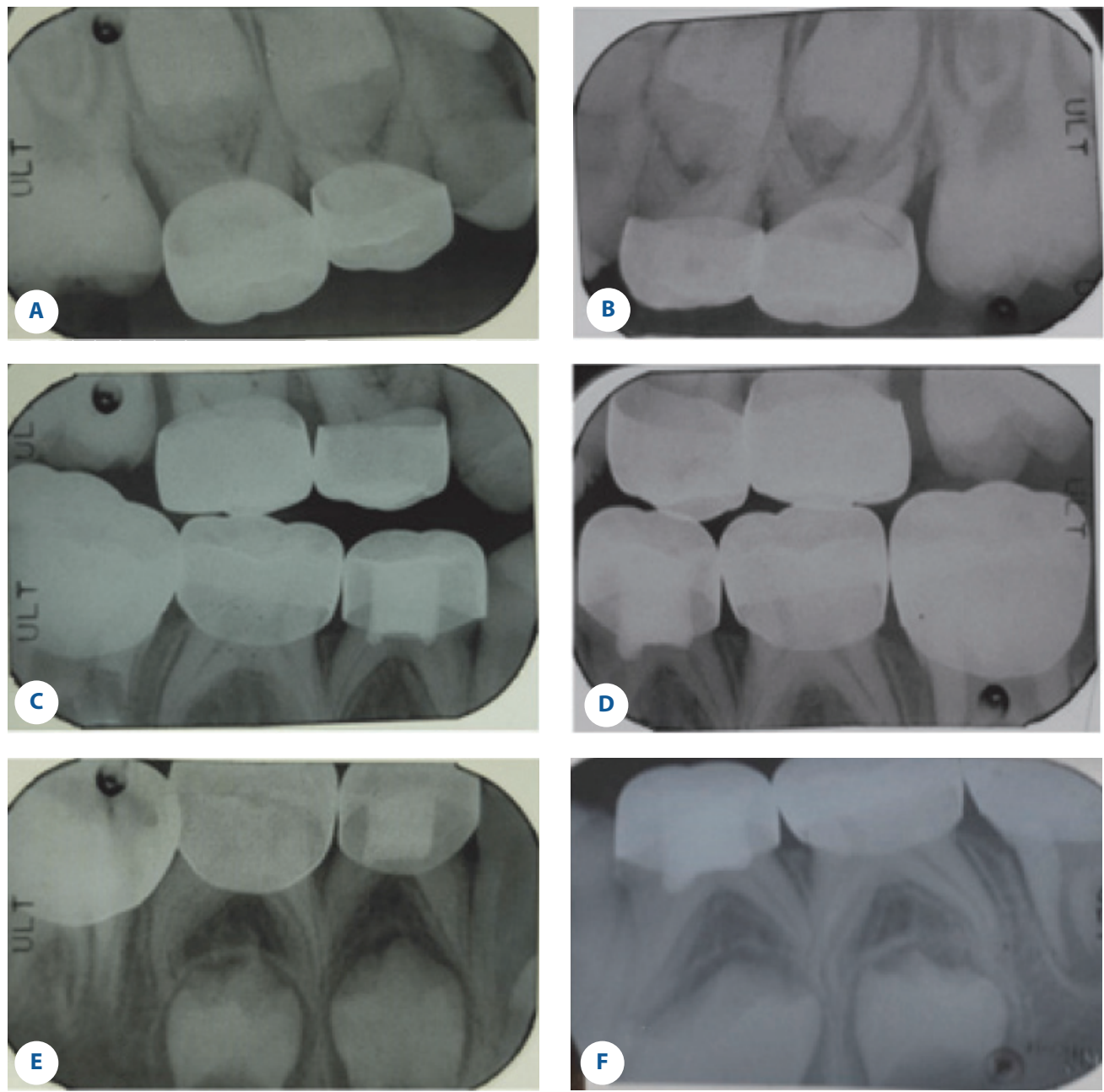

Figure 10A-F. Three months' post-operative radiographs. 
Multidisciplinary Treatment Approach of a Patient with Amelogenesis Imperfecta Superimposed by Thumb Sucking Habit... R.R. Gholman and O.A. El Meligy

cribs. The wire component with the cribs was soldered to the bands on primary second molars.

2. Prophy and fluoride application using $5 \%$ sodium fluoride $(\mathrm{NaF})$ was done.

3. Oral hygiene instructions were reinforced.

4. The appliance was cemented using glass ionomer cement (GC Fuji 1) (Fig. 8), then the patient was followed-up once every month to assess oral hygiene, compliance, appliance efficiency and to activate the quad-helix.

After 3 months, parents were satisfied reporting that their son discontinued the habit and they noticed a change in his facial as well as dental appearance. Upon clinical examination, posterior cross bite was corrected successfully with reduced open bite, but still not the optimal so, the appliance was kept as a habit breaking device without activation and the patient was still under treatment. The use of resinbased composites and SSCs produced effective and satisfying improvement of the patient's aesthetic looks, in addition to prevention of further sensitivity and wear so enhancing his functional needs. All the restorations are intact with no signs of fracture, staining, cracking, or dental caries (Figs. 9 and 10). Oral hygiene improved during recall visits and the gingival tissue healed with no inflammation.

\section{Conclusions}

The following conclusions can be made:

1. There is a major role for the multidisciplinary team in the effective management of patients with hypomaturation type of Al.

2. Many factors have a significant part in treatment planning of Al cases such as patient's age, socioeconomic condition, seriousness of the defect, the patient's collaboration and association with other medical conditions.

3. Medical screening is important in Al cases due to association of Al with many conditions such as bicytopenia, or platyspondyly.

\section{Conflict of Interest}

The authors had no conflict of interest.

\section{Disclosure}

The authors did not receive any type of commercial support either in forms of compensation or financial for this study. The author has no financial interest in any of the products or devices, or drugs mentioned in this article.

\section{Ethical Approval}

Obtained.

\section{References}

[1] Wright JT, Torain M, Long K, Seow K, Crawford P, Aldred MJ, Hart PS, Hart TC. Amelogenesis imperfecta: Genotypephenotype studies in 71 families. Cells Tissues Organs 2011; 194: 279-283

[2] Backman B, Holmgren G. Amelogenesis imperfecta: A genetic study. Hum Hered 1998; 38: 189-206.

[3] Stern BM. A multidisciplinary approach to the functional and esthetic rehabilitation of amelogenesis imperfect and open bite deformity: A case report. J Esthet Restor Dent 2010; 22: 282296.

[4] Lindemeyer RG, Gibson CW, Wright TJ. Amelogenesis imperfecta due to a mutation of the enamelin gene: Clinical case with genotypephenotype correlations. Pediatr Dent 2010; 32: 5660.

[5] Pavliĉ A, Battelino T, Podkrajsek KT, Ovsenik M. Craniofacial characteristics and genotypes of amelogenesis imperfecta patients. Eur J Orthod 2001; 33: 325331.

[6] Winter GB, Brook AH. Enamel hypoplasia and anomalies of the enamel. Dent Clin North Am 1997; 19: 324

[7] de La Dure-Molla M, Philippe Fournier B, Berdal A. Isolated dentinogenesis imperfecta and dentin dysplasia: revision of the classification. Eur J Hum Genet 2015; 23: 445-451.

[8] Witkop CJ Jr. Amelogenesis imperfecta, dentinogenesis imperfecta and dentin dysplasia revisited: problems in classification. J Oral Pathol 1998; 17: 547-553.

[9] Rodd HD, Abdul-Karim A, Yesudian G, O'Mahony J, Marshman Z. Seeking children's perspectives in the management of visible enamel defects. Int J Paediatr Dent 2011; 21: 89-95.

[10] Markovic D, Petrovic B, Peric T. Case series: clinical findings and oral rehabilitation of patients with amelogenesis imperfecta. Eur Arch Paediatr Dent 2010; 11: 201-208.

[11] Sabatini C, Guzman-Armstrong S. A conservative treatment for amelogenesis imperfecta with direct resin composite restorations: a case report. J Esthet Restor Dent 2009; 21: 161-169.

[12] Gisler V, Enkling N, Zix J, Kim K, Kellerhoff NM, MericskeStern R. A multidisciplinary approach to the functional and esthetic rehabilitation of amelogenesis imperfecta and open bite deformity: a case report. J Esthet Restor Dent 2010; 22: 282-293.

[13] Bharath Shetty Y, Shetty A. Oral rehabilitation of a young adult with amelogenesis imperfecta: a clinical report. J Indian Prosthodont Soc 2010; 10: 240-245. 
Multidisciplinary Treatment Approach of a Patient with Amelogenesis Imperfecta Superimposed by Thumb Sucking Habit... R.R. Gholman and O.A. El Meligy

[14] Ramos AL, Pascotto RC, Iwaki Filho L, Hayacibara RM, Boselli G. Interdisciplinary treatment for a patient with open-bite malocclusion and amelogenesis imperfecta. Am J Orthod Dentofacial Orthop 2011; 139: S145-S153.

[15] Venezie RD. Enamel pretreatment with sodium hypochlorite to enhance bonding in hypocalcified amelogenesis imperfecta: case report and SEM analysis. Pediatr Dent 1994; 16: 433-436. 
نهج العلاج متعدد التخصصات لمريض نقص التشوء مثراكب بعادة مص الابهام: تقريز حالة

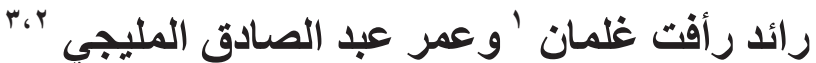

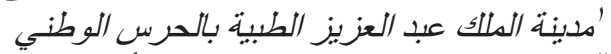

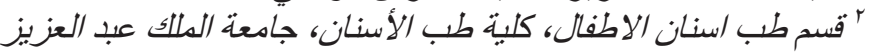

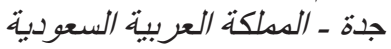

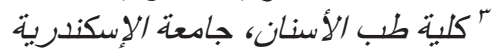

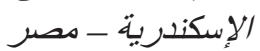

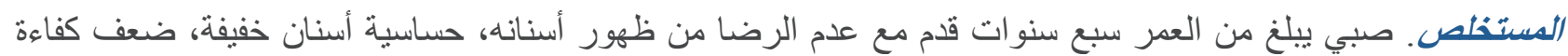

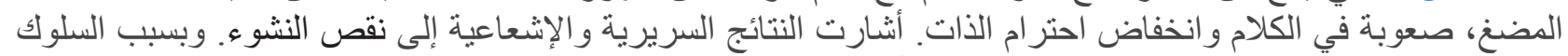

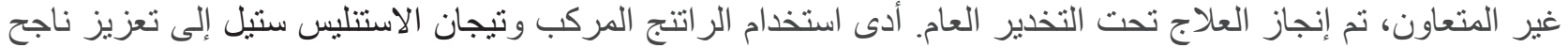

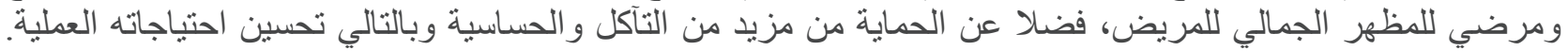

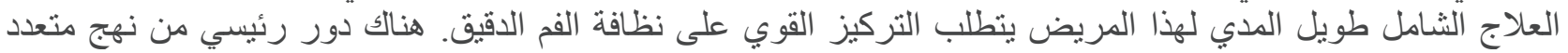

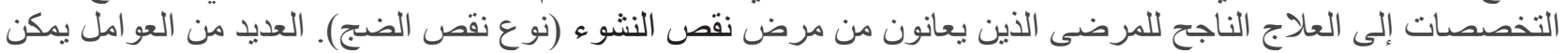

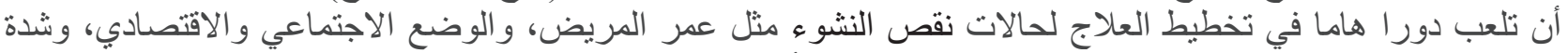
الاضطر اب، وتعاون المريض و علاقته دع الحالات الطبية الأخرى. 